\title{
A generic converter for experimentation based power electronics learning
}

\author{
Vicente Leite ${ }^{1}$, José Barbosa ${ }^{2}$, Henrique Teixeira ${ }^{3}$ and Rui Esteves Araújo ${ }^{4}$ \\ ${ }^{1,2,3}$ INSTITUTO POLITÉCNICO DE BRAGANÇA \\ Campus de Santa Apolónia, apartado 134, 5301-857 Bragança \\ Bragança, Portugal \\ Tel.: +351/273303158 \\ Fax: $+351 / 273313051$ \\ ${ }^{4}$ FACULDADE DE ENGENHARIA DA UNIVERSIDADE DO PORTO \\ Rua Dr. Roberto Frias s/n, 4200-465 Porto \\ Porto, Portugal \\ Tel.: +351/22508 1808 \\ Fax: +351/22 5081443 \\ E-Mail: ${ }^{1}$ avtl@ipb.pt, ${ }^{2}$ jbarbosa@ipb.pt, ${ }^{3}$ hteixeira@ipb.pt and ${ }^{4}$ raraujo@fe.up.pt \\ URL: http://www.ipb.pt, www.fe.up.pt
}

\section{Keywords}

«Education tool», «Education methodology», «Voltage Source Inverters (VSI) », «Adjustable speed drive», «EMC/EMI»

\begin{abstract}
This paper presents a low cost, modular, configurable and fully protected education tool based on a generic electronic converter to be used by students, providing them with skills regarding power electronics and converters, and enabling them to learn from experience the most important issues concerning DC and $\mathrm{AC}$ electric drives.
\end{abstract}

\section{Introduction}

The field of power electronics and electric drives has increased enormously in the most recent decades. Its importance is patent on the great number of meetings and conferences promoted, the increasing number of publications and the large number of industrial and home applications, vehicular propulsion, and power distribution. Moreover, the field of power electronics is to increase extraordinary in the coming years. However, courses in electric machines and electric drives, for instance, are suffering from lack of student's interest leading to their cancellation and eventual elimination from the curriculum, all over the world, [1]. As a result of the decline in the number of students who study technical areas in general, Universities experiment innovations in the curricula [1] - [4], to make their courses more attractive and searching for new ways of teaching to make these subjects more interesting and understandable to students [1] - [11]. Most of these works describe and propose new education methodologies [1] - [4], and/or education tools based on software [12] - [14], including web-based teaching [14], hardware [7] - [9], [11], [15] and [16], and the integration of both [5], [6], [10], [13], [17] and [18], being some of these advanced and expensive platforms [10], [18].

The subjects of traditional technical areas in general, and power electronics, electric machines and electric drives, in particular, are considered by the students as old-fashioned, staid and boring [1], and other 
reasons for the lack of motivation of students are referred in [3]. To go against this problematic tendency the authors of [1] suggest that the focus could be shifted from electric machines to electric drives allowing the introduction of this subject in the context of exciting new applications. In other works it is believed that up-to-date computer hardware and software tools and information technologies, in both lecture and laboratory classes, can meet the expectations of today's students and attract other students [5], [12]. In [2] is described how a motivating learning environment has leaded to a significant increase of students studying electric machines and variable speed drives. Virtual instruments and web-based teaching in power electronics is also being used [14], [17], to improve the students motivation and successful. In fact, the task is not easy since this field of electrical engineering requires a large amount of knowledge regarding power electronics, electromagnetism and electric machines, circuit and signal analysis, digital control and signal processing, measuring electronics, and so forth. Hence, students are "invited" to increase their theoretical knowledge without sufficient details and explanations. This is a real challenge for students and teachers and it is a matter of fact that practical experimentation is being more and more reduced. On the other hand, the demand for highly skilled engineers in the field of power electronics and electric drives can only be met if today's students develop their skills in very important and practical issues. Furthermore, universities worldwide are paying more and more attention to hard issues of growing importance such as electromagnetic interference (EMI) and electromagnetic compatibility (EMC) [15]. There is no doubt about the relevance of this topic nowadays [19] - [24].

The process resulting from Bologna declaration [25] is being implemented all over European Community and other countries. It establishes a new education system for a Europe of knowledge being a challenge for higher education in view of the globalization in science, technology, and economy. According to Bologna process implementation and by all the previous reasons the focus of the education methodology needs to be shifted from teaching to learning: experimentation and project based learning. Teachers play an important role in simulation of student's interest in electric machines and power electronics by providing them with practical skills and experience in electronic design, by means of suitable instruments and education tools, being [7] - [9], [11], [15] and [16] some examples.

\section{Motivation}

In the context of previous section the present paper describes and proposes a generic electronic converter as an education tool for power electronics and electric drives learning based on experimentation which can be used by students to learn from experience the most important issues about power electronics, converters, and electric drives, including the ones regarding EMI/EMC [19] - [24]. This work was developed in order to solve some of the difficulties described in the introduction section, and motivated by the lack of commercial products with similar technical characteristics and requirements, namely: low cost, open (i.e. with access to all signals), modular and configurable, using components easily available, repairable in the laboratory, with galvanic isolation, effectively protected, easily understandable and built/mounted by students. Although it has been thought for educational purposes it is being also used in I\&D activities. To improve the physical packaging some arrangements are being carried out. Commercial products are now available like [26] and [27], for instance, but without all these requisites fulfilled.

\section{Description of the generic converter}

A set of pieces were designed in order to build a low cost, modular, configurable, fully protected and isolated electronic converter as shown in fig. 1. Fig. 2 shows some photos of a Voltage Source Inverter (VSI) configuration connected to the power line and feeding a $3 \mathrm{~kW}$ induction motor. Each piece works as a module of several possible converter topologies such as single- and three-phase VSIs, one-, two- or fourquadrant DC-DC converter configurations, which can be used in AC or DC motor drives, for instance. 


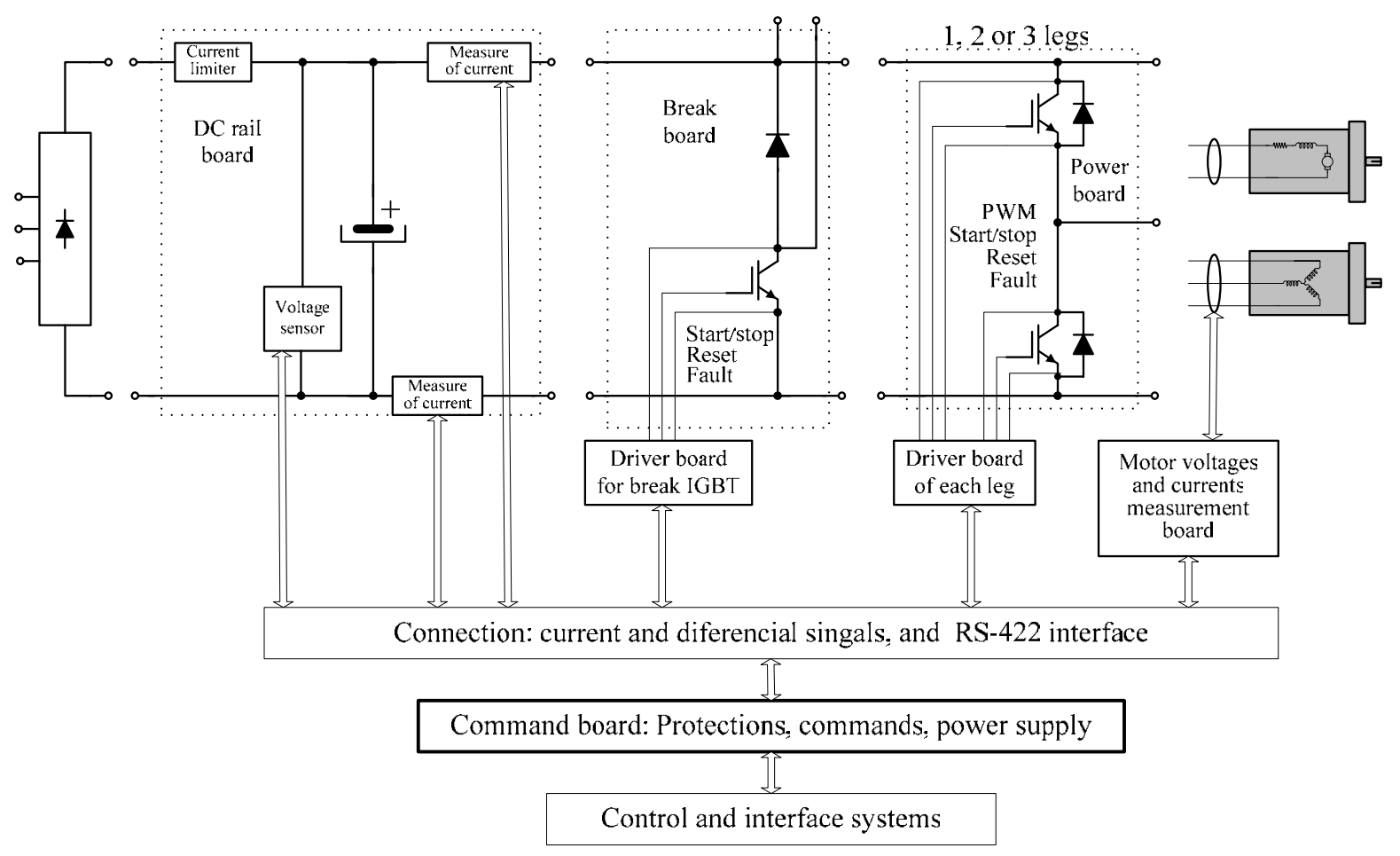

Fig. 1: Electronic converter diagram.
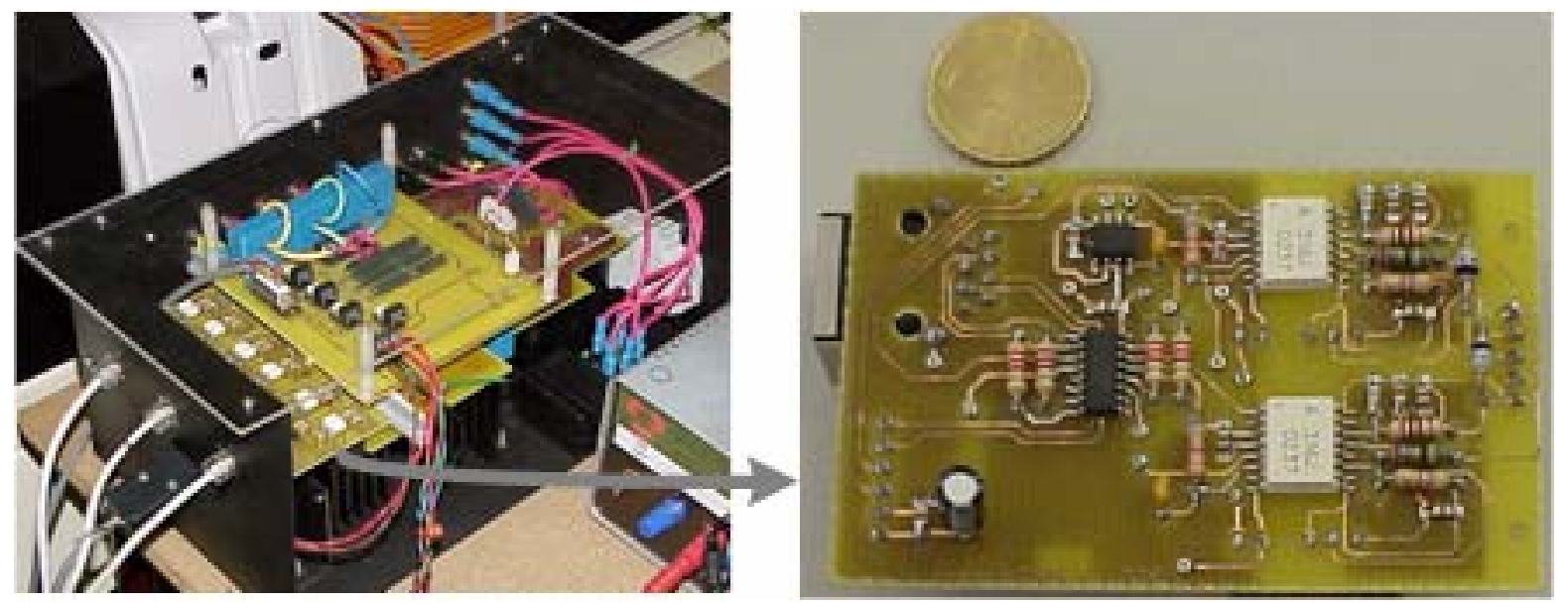

Fig. 2: Electronic converter. VSI configuration and the driver board for one leg, on the left- and right-hand side, respectively.

The main modules or boards that integrate the developed generic converter are the following:

- an integrated input diode-rectifier, ref. 36MT120;

- a DC bus board with filter capacitors and shunt resistors for over-current and short-circuit protection; 
- a power board with one- two- or three-leg (and can be even more) based on discrete IGBTs;

- a signal distribution board to distribute the command signals: reset, start/stop and fault;

- the driver board to control each leg individually (shown in fig. 2, on the right-hand side);

- a command board and

- the measurement board.

\section{The DC bus board}

The DC bus board basically includes the positive and negative rails with a shunt resistor in each one of them for additional over-current and short-circuit protection, four electrolytic capacitors and a NTC resister as a current limiter whenever they are charged. Two precision resistors are connected between the positive and negative rails for DC voltage measurement.

\section{The power board}

According to the requirements of the generic converter proposed in this paper the best way to build the power board is to design different power boards each of them with one heat sink and one, two, three or more legs considering the converter topology required. It improves the robustness of the converter. Whatever the number of legs is used, each of them is controlled independently from the others by means of its own driver board and cable enabling us to build several converter topologies. The discrete semiconductors used in the converter legs are 1200V, 24A (@ $\mathrm{T}_{\mathrm{C}}=100^{\circ} \mathrm{C}$ ) discrete IGBTs, ref. IRG4PH50KD, from International Rectifier.

Modularity and flexibility are two important requirements of this project. These are not completely compatible with the best practices regarding EMI emissions. In fact, this issue has been gaining more attention than before in the universities [15]. Considering EMI noises generated by high $d i / d t$ and $d v / d t$, the converter should be as compact as possible in view of a suitable control of differential and commonmode currents. This strongly influences the layout of the power and DC bus boards. Therefore, some aspects of the methods proposed in [23] were taken in consideration. Thus, critical distances were made as short as possible, positive and negative rails are laminated and a similar packaging was adopted.

\section{The signal distribution board}

This board is very simple and its function is just to distribute the reset and start/stop signals from the command board to the driver board of each leg and collect the fault signal from each driver board to the command board. The same distribution board is used independently of the number of legs used in the power board or converter topology.

\section{The driver board}

The driver board for each leg is based on two HCPL-316J gate drivers [28] to control de upper and lower IGBTs of the converter leg. By adjusting one resistor, the HCPL-316J can drive IGBTs up to $\mathrm{I}_{\mathrm{C}}=150 \mathrm{~A}$ and $\mathrm{V}_{\mathrm{CE}}=1200 \mathrm{~V}$. It includes galvanic isolation and integrated fail-safe IGBT protection: desat $\left(\mathrm{V}_{\mathrm{CE}}\right)$ detection and under voltage lock-out (UVLO) protection with hysterisis and performs "soft" IGBT turn-off. By using the HCPL-316J gate driver optocoupler with integrated desaturation $\left(\mathrm{V}_{\mathrm{CE}}\right)$ detection and isolated fault status feedback makes IGBT $\mathrm{V}_{\mathrm{CE}}$ fault protection compact, affordable, easy-to-implement while satisfying worldwide safety and regulatory requirements [28].

Bootstrapped output power supply circuits were implemented to provide output power to the HCPL-316J gate driver optocouplers [29]. These circuits have the following benefits: eliminates the need for isolated and floating power supplies, is a lower cost solution compared to transformer based power supplies or isolated DC to DC converters (one for each optocoupler, two for each leg), and occupies less printed circuit board space. 


\section{The command board}

The command board receives the fault signals from the driver boards of each converter leg and the fault signal from the DC bus board corresponding to an over-current or short-circuit fault. Whenever a fault occurs, the PWM signals are disabled, the fault origin is signalled by means of a led, and the fault is memorized until a reset command is sent. The PWM signals are sent or stopped according to a start/stop command and the status of the fault signal. All these fundamental command signals can be set locally by hardware or by a host controller board.

The connection between the command and each of the driver boards is performed by means of a RS-422 interface, enabling suitable distances between the control and power boards.

\section{The measurement board}

Considering the educational purposes of the generic converter a measurement board was built in order to measure the DC rail current and one, two or three phase currents. All the currents are measured using halleffect sensors, ref. LA 55P. The DC bus voltage and the converter output voltages, until the number of three, can be measured by means of simple circuits based on the isolation amplifier HCPL-7800.

The transmission of the measured voltage and current signals is performed in differential mode and current signal, respectively. The benefit of this solution, together with the RS-422 interface used for PWM signals, is that suitable distances can be used between the control and power systems with noise immunity.

\section{Some experimental illustrations}

In this section some experimental results are shown to demonstrate how the generic converter can be used. For example, the VSI configuration of fig. 2 is used as an experimental learning set-up for a $3 \mathrm{~kW}$ induction motor adjustable speed drive. The induction motor is controlled using a scalar control which maintains a constant volt per hertz $(\mathrm{V} / \mathrm{Hz})$ ratio. The switching frequency was programmed to $5 \mathrm{kHz}$.

In this experiment there are two important issues of interest to analyse: the generated PWM signals and the difficulties resulting from such signals. The first is widely described in literature and can be simulated with a large amount of software. However, it should be complemented with experimental verification. Otherwise, students will never feel the second issue concerning EMI when fast switches are used nowadays like IGBTs. The main issues about EMI emissions in power electronics and electric drives have been studied and the references [19] - [22] and [24] are just some very good examples. The objective here is just to demonstrate how easy is to show experimentally some of these important and practical issues, using the developed generic converter.

In spite of the main advantages of VSI such as high efficiency, small relative size, excellent regulation capabilities, wide speed range, high constant input power factor, among others, the output voltages resulting from the PWM pulses with high $d v / d t$ present some problems regarding EMI emissions when fast switching semiconductors are used to achieve high efficiency. Therefore, common mode voltages with high $d v / d t$ in the cable connecting the VSI to the motor is a potential source of EMI and that is the reason why usually shielded cables are used or other solutions should be considered [21], otherwise susceptible equipment will be perturbed. But, on the other hand, when shielded cables are used, common mode currents are present resulting from the combination of high $d v / d t$ pulses in the output voltage and the parasitic cable capacitances.

Fig. 3 shows a simplified diagram of the connection between a VSI configuration of the converter and the induction motor using a suitable shielded cable. The simplified model of fig. 3 shows potential coupling mechanisms of common mode noises in modern PWM drives [19]. 


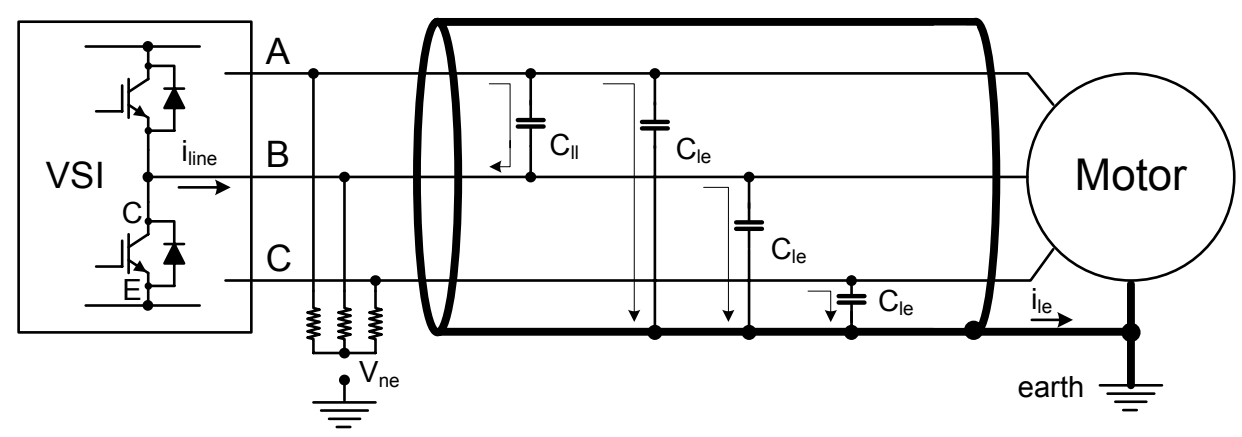

Fig. 3: Simplified diagram of the connection between VSI and motor showing some details concerning parasitic cable capacitances responsible for the line-to-earth current $i_{\text {le }}$.

In order to show these coupling mechanisms resulting in common mode noise, a simple experience can be used, starting from the set-up of fig. 3 . Thus, a $20 \mathrm{~m}$ shielded cable was used for the connection between the VSI and the induction motor. Fig. 3 shows some details concerning to parasitic cable capacitances which are responsible for the line-to-earth current $\mathrm{i}_{\mathrm{le}} . \mathrm{C}_{\mathrm{le}}$ represents the parasitic capacitance between each line and the shield that is connected to the earth. As referred above shielded cables prevent susceptible equipment from radiated noise but, on the other hand, contribute to conduit noise as illustrated in fig. 3 . Total line-to-earth current $i_{\mathrm{le}}$ is the sum of all transient currents resulting from the voltage commutations $\left(\mathrm{i}_{\mathrm{C}}=\mathrm{C} \times d v / d t\right) . \mathrm{V}_{\mathrm{ne}}$ consists of a neutral-to-earth voltage which is behind the $\mathrm{i}_{\mathrm{le}}$ current sourced from the VSI. Students can easily understand how these currents are generated by considering the illustration shown in fig. 4.

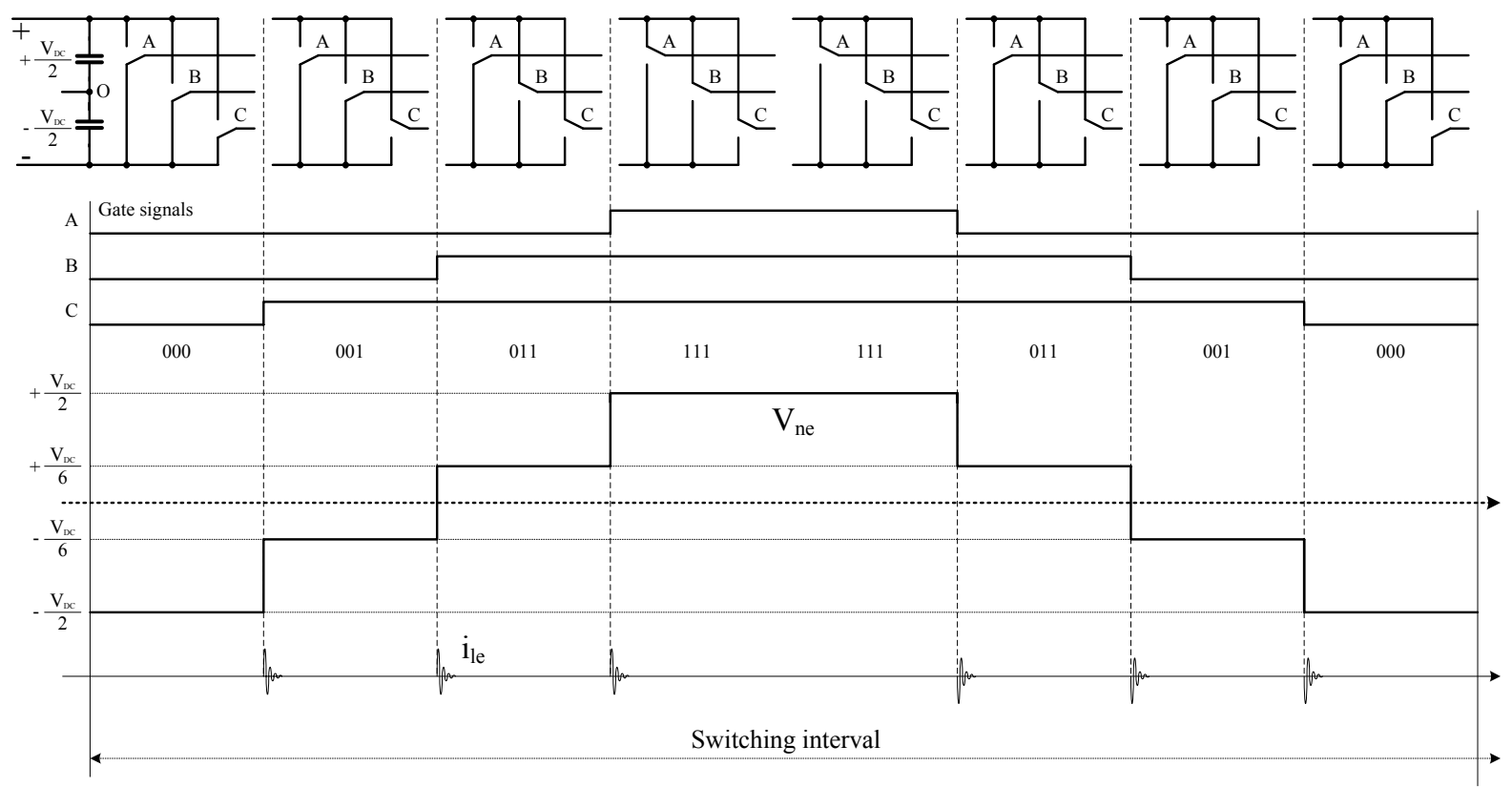

Fig. 4: Illustration of the common mode voltage and current generation in an AC PWM adjustable speed drive. 
PWM voltages from VSI also generate common mode voltages because of asymmetrical voltage pulses. The switching pattern shown in fig. 4 can be used to demonstrate how the common mode voltage, $V_{\text {ne, }}$, is generated. This voltage results from the average voltage of the three VSI legs, that is: $V_{n e}=\left(V_{A}+V_{B}+V_{C}\right) / 3$.

Considering the mid-point, $\mathrm{O}$, of the $\mathrm{DC}$ bus as a reference, and $\mathrm{V}_{\mathrm{DC}}$ the corresponding voltage, the three voltages, $V_{A}, V_{B}$ and $V_{C}$, can either be $\pm V_{D C} / 2$ or $\pm V_{D C} / 6$, according to the state of the switches, as shown in fig. 4. Due to this, the three-phase VSI can not have an output common mode voltage equal to zero. Some results of this experiment, based on fig. 3, are shown in fig. 5(a) to (h).

Fig. 5(a) shows a detail of the $V_{C E}$ voltage across the lower IGBT in fig. 3 and its turn-on command signal. The same $\mathrm{V}_{\mathrm{CE}}$ voltage is shown in fig. 5(b) together with the motor current corresponding to the leg of that IGBT. In fig. 5(c) we can see the motor current and the line-to-motor neutral point (Y connected). The amount of $\mathrm{i}_{\mathrm{le}}$ current (due to $\mathrm{C}_{\mathrm{le}} \times d v / d t$ transient currents) is clearly visible in fig. 5(d). In fig. 5(e) the line-to-line voltage and $i_{\mathrm{le}}$ current are shown and the magnitude of the $\mathrm{i}_{\mathrm{le}}$ spikes is higher than 6A. Fig. 5(e) is expanded in fig. 5(f). The neutral-to-earth voltage $V_{\text {ne }}$, and current $i_{\mathrm{le}}$, are shown in fig. $5(\mathrm{~g})$ which is expanded in fig. $5(\mathrm{~h})$. The origin of the common mode voltage and current generation, $\mathrm{V}_{\mathrm{ne}}$ and $i_{\text {le }}$ respectively, in an AC PWM adjustable speed drive is illustrated in fig. 4 and was describe above. The frequency of the $\mathrm{V}_{\text {ne }}$ voltage is the switching frequency and its amplitude is modulated by low and high $150 \mathrm{~Hz}$ ripple components due to the 3 pulse voltage at the input diode-rectifier, from "+" and "-." terminals to earth. To see the common voltage $V_{\text {ne }}$ correctly, and the corresponding current $i_{\text {le }}$, high bandwidth probes (higher than 10MHz) must be used which was not possible, in this experiment, in the case of the current $i_{\mathrm{le}}$ measurement because a high bandwidth current probe was not available.

The above experiment is related to the VSI configuration of the generic convert described in this paper and associated EMI issues in AC drives. However, the converter can be used as a general framework in power electronics and drives. A final example of the configurability of the converter is shown in fig. 6 , where a DC drive is implemented. Two legs are used to build a full-bridge DC-DC converter in order to control a DC motor in all quadrants and a third leg is used to control the field of separately-excited DC motor.

Since the converter can be used as a set of pieces, an almost unlimited number of experiences can be performed regarding power electronics, power converters and PWM patterns, and AC and DC electric drives in open and closed loop control.

\section{Conclusion}

Students need to be provided with experimental skills and experience in power electronics practical issues using suitable educational tools. The education methodology needs to be shifted from teaching to learning by means of experimentation and project based learning. In this paper, a generic and configurable converter was presented and is proposed for power electronics learning based on experimentation. It can be used by students to learn from experience the most important issues concerning power electronics, converters, and DC and AC electric drives. The main advantages of such a generic converter are summarised as follows: low cost since only commercial components are used which can be easily found; it can be easily repaired with low cost because it uses discrete (and low cost) components and is repaired in the laboratory; it can be easily configurable since it has a modular structure based on simple electronic modules; fully protected against short-circuits, over-current and under- and over-DC bus voltage; completely open and with the most important measures easily accessible. 


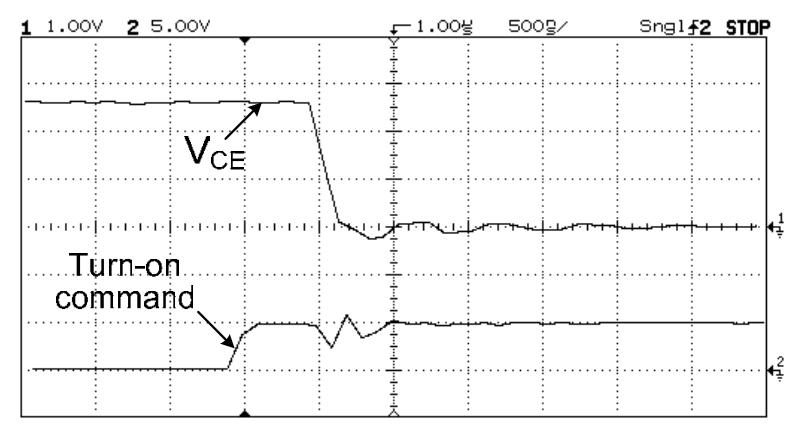

(a)

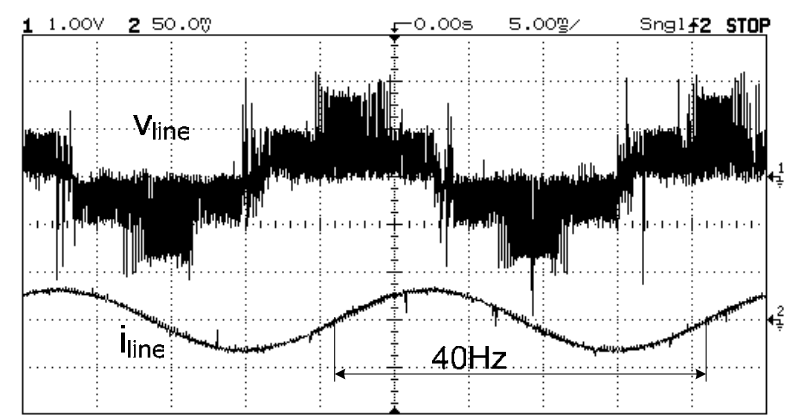

(c)

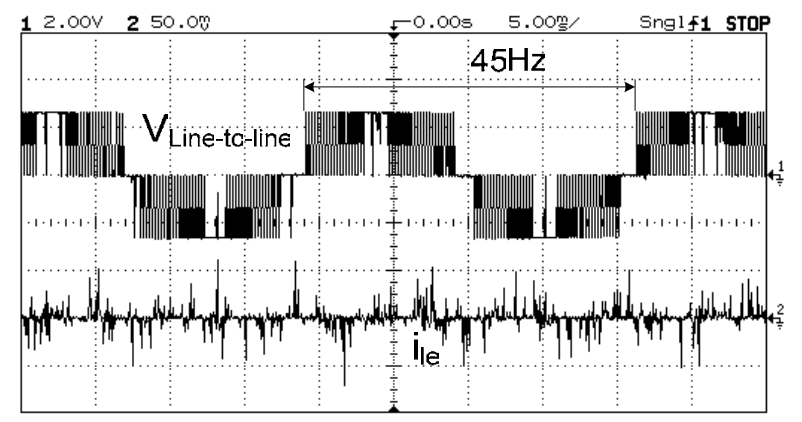

(e)

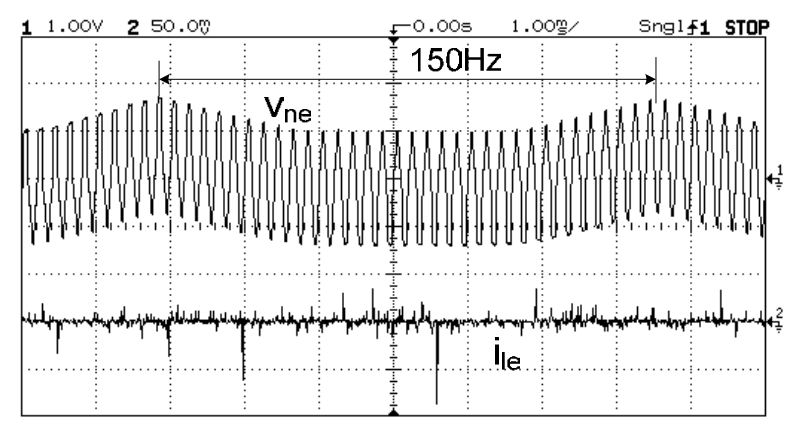

(g)

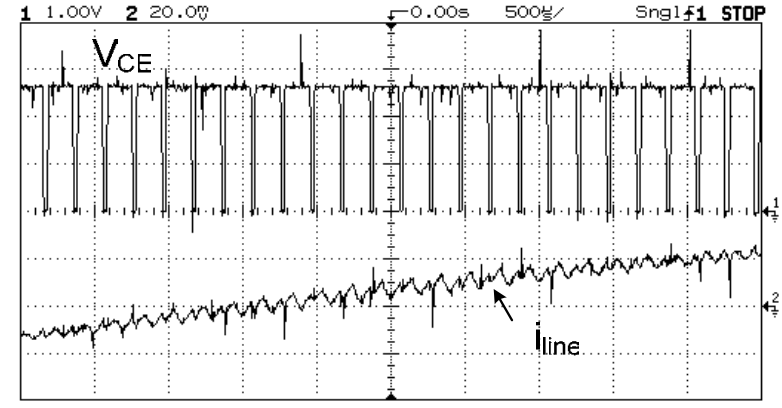

(b)

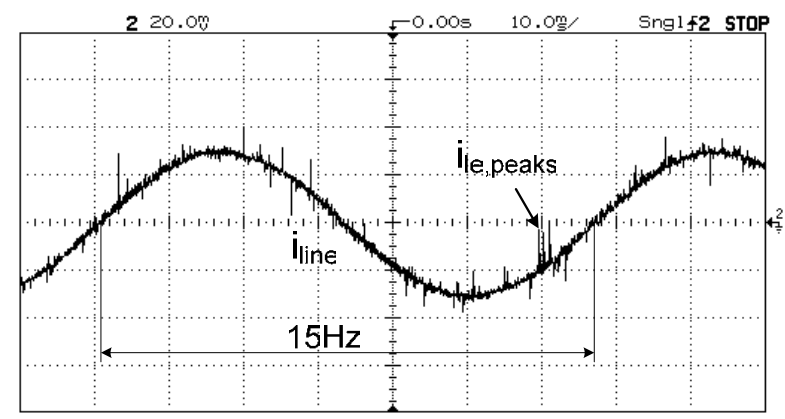

(d)

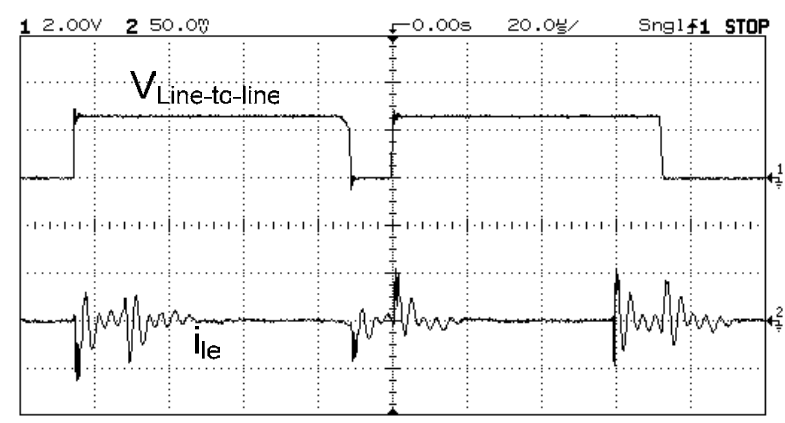

(f)

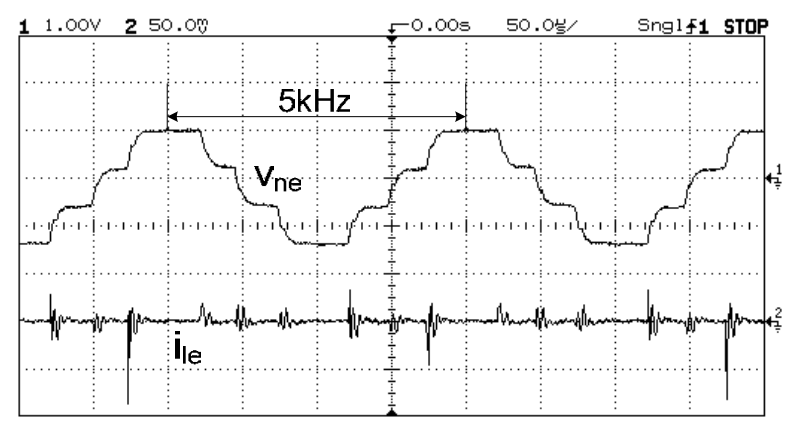

(h)

Fig. 5: Some experimental illustrations for the experiment based on fig. 3. Scales for voltages and currents are $\times 200 \mathrm{~V} / \mathrm{V}$ and $\times 1 \mathrm{~A} / 10 \mathrm{mV}$, respectively. 


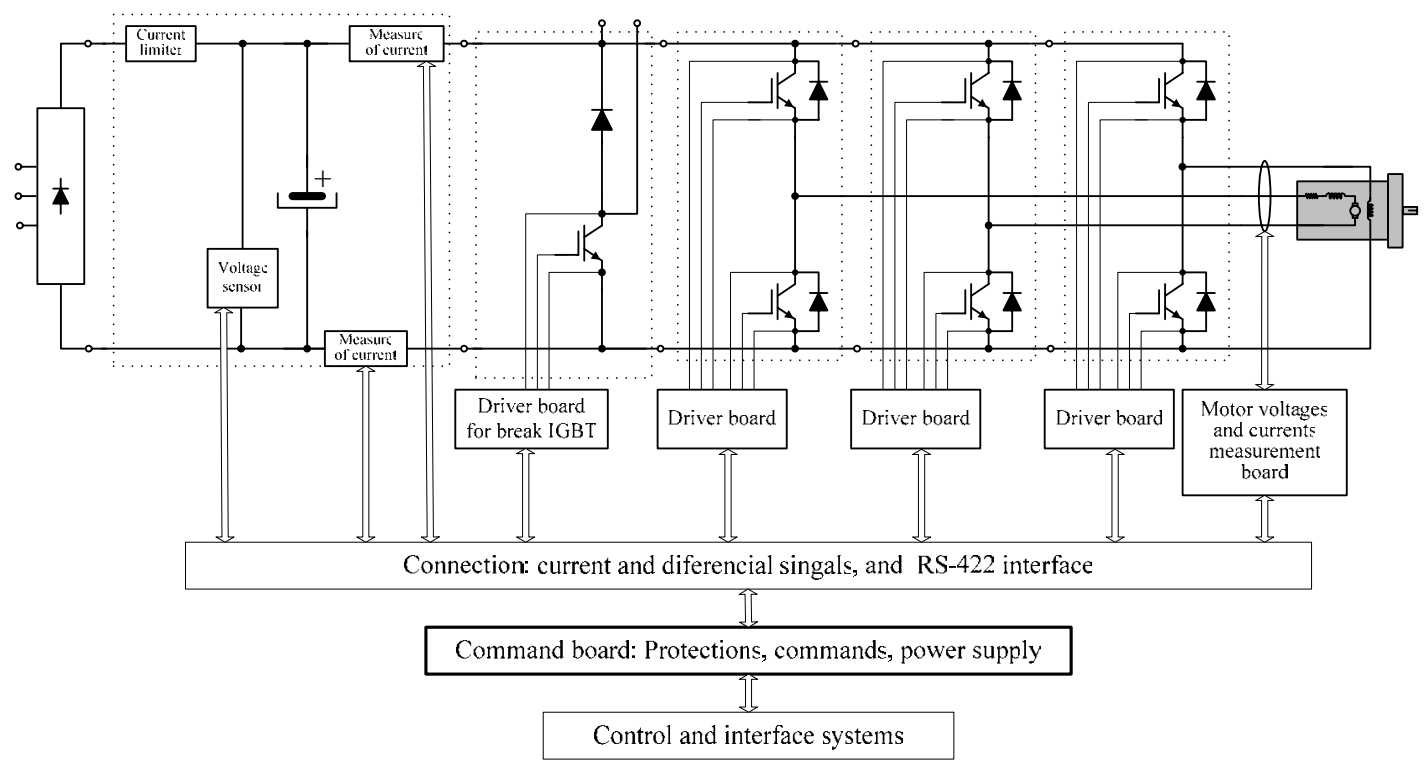

Fig. 6: Example of DC electric drive using the generic converter.

\section{References}

[1]. T. Undeland, N. Mohan, Teaching Electric Machines and Drives: A Re-examination for the New Millenium, in Proc. EPE-PEMC'02, Dubrovnic \& Cavtat, Croatia, July, 2002.

[2]. C. Saniter, T. Sadowski, R. Hanitsch, Implementation of a Motivating Environment for Electrical Drive Engineers at the Technical University of Berlin, in Proceedings of $10^{\text {th }}$ European Conference on Power Electronics and Applications - EPE 2003, Toulouse, France, September 2-4, 2003.

[3]. F. Blaabjerg, M. P. Kazmierkowski, J. K. Pederson, P. Thørgersen, M. Tønnes, An Industry-University Collaboration in Power Electronics and Drives, in IEEE Trans. on Education, vol. 43, N. ${ }^{\circ}$ 1, pp. 52-57, February, 2000.

[4]. G. G. Karady, G. T. Heydt, Increasing Student Interest and Comprehension in Power Engineering at the Graduate and Undergraduate Levels, in IEEE Trans. on Power Systems, vol. 15, N. ${ }^{\circ}$, pp. 16-21, February, 2000.

[5]. S. Ayasun, C. O. Nwankpa, Induction Motor Tests Using MATLAB/Simulink and Their Integration Into Undergraduate Electric Machinery Courses, in IEEE Trans. on Education, vol. 48, N. ${ }^{\circ}$ 1, pp. 37-46, February, 2005.

[6]. J. M. Williams, J. L. Cole, N. D. Benavides, J. D. Wooldridge, A. C. Koenig, J. L. Tichenor, S. D. Pekarek, Versatil Hardware and Software Tools for Education Students in Power Electronics, in IEEE Trans. on Education, vol. 47, N. ${ }^{\circ}$ 4, pp. 436-445, November, 2004.

[7]. S. A. Shirsavar, Teaching Practical Design of Switch-Mode Power Supplies, in IEEE Trans. on Education, vol. 47, N. ${ }^{\circ}$ 4, pp. 467-473, November, 2004.

[8]. V. Leite, H. Teixeira, F. Casais, R. Araújo, D. Freitas, A Real-Time Monitoring Instrument of Induction Machines for an Iintegrated Teaching Test Bench, 8CLEEE, in Proceedings of $8^{\text {th }}$ Portuguese-Spanish Congress on Electrical Engineering - 8CLEEE, Vilamoura, Portugal, July 4-5, 2003.

[9]. R. Araújo, V. Leite, D. Freitas, A Low Cost Solution for Laboratory Experiments in Induction Motor Control, in Proceedings of EPE'03, Toulouse, France, September 2-4, 2003.

[10]. R. Teodorescu, M. Bech, A. Jorgensen, K. Larsen, F. Blaabjerg, J. Pedersen, Advanced Prototyping Tools for Project- and Problem-Based Learning, in Proceedings of EPE-PEMC02, Dubrovnic \& Cavtat, Croatia, July, 2002. 
[11]. R. Round, Converter Design for a Model Solar Car, in Proceedings of EPE-PEMC02, Dubrovnic \& Cavtat, Croatia, July, 2002.

[12]. A. M.-Muñoz, V. Pallarés, J. Luna, J. M. Flores, Switching Mode Power E-Learning Toolbox, in Proceedings of $10^{\text {th }}$ European Conference on Power Electronics and Applications - EPE 2003, Toulouse, France, September 2-4, 2003.

[13]. D. Sumina, N. Bulic, G. Erceg, Implementation of an Industrial Drive control System in Education Process, in Proceedings of $10^{\text {th }}$ European Conference on Power Electronics and Applications - EPE 2003, Toulouse, France, September 2-4, 2003.

[14]. Ł. Starzak, M. Zubert, B. Świercz, A. Napieralski, Web-Based simulation of power Circuits and Teaching, in Proceedings of $10^{\text {th }}$ European Conference on Power Electronics and Applications - EPE 2003, Toulouse, France, September 2-4, 2003.

[15]. Y. Zhao, K. Y. See, A Practical Approach to EMC Education at the Undergraduate Level, in IEEE Trans. on Education, vol. 47, N. ${ }^{\circ}$ 4, pp. 425-429, November, 2004.

[16]. R. Araújo, J. Gonçalves, D. Freitas, An Instrument for Measurement of Induction Motor drives Based on Phasor and Modelling Techniques, IEEE Trans. on Energy Conversion, vol. 14, nº 3, pp. 704-711, 1999.

[17]. Ž. Jakopović, Z. Benčić, V. Šunde, Virtual Laboratory for Power Electronics, in Proceedings of $10^{\text {th }}$ European Conference on Power Electronics and Applications - EPE 2003, Toulouse, France, September 2-4, 2003.

[18]. R. Bojoi, F. Profumo, G. Griva, R. Teodorescu, F. Blaabjerg, Advanced Research and Education in Electrical Drives by Using Digital Real-Time Hardware-in-Loop Simulation, in Proceedings of EPE-PEMC02, Dubrovnic \& Cavtat, Croatia, July, 2002.

[19]. G. L. Skibinski, R. J. Kerkman, D. Schlegel, EMI Emissions of Modern PWM ac Drives, in IEEE Ind. Applications Magazine, November/December, pp. 47-81, 1999.

[20]. L. Rossetto, P. Tenti, A. Zuccato, Electromagnetic Compatibility Issues in Industrial Equipement, in IEEE Ind. Applications Magazine, November/December, pp. 34-46, 1999.

[21]. N. Hanigovszki, J. Poulsen, G. Spiazzi, F. Blaabjerg, An EMC Evaluation of the Use of Unshielded Motor Cables in AC Adjustable Speed Drives, in Proceedings of PESC'04, pp. 75-81, Aachen, Germany, June 2025, 2004.

[22]. G. Grandi, D. Casadei, U. Reggiani, Common- and Differential-Mode HF Current Components in AC Motors Supplied by Voltage Source Inverters, in IEEE Trans. on Power Electronics, vol. 19, N.o 1, pp. 16-24, January, 2004.

[23]. N. Mutoh, M. Ogata, New Methods to Control EMI Noises Generated in Motor Drive Systems, in IEEE Trans. on Ind. Applications, vol. 40, N. ${ }^{\circ}$ 1, pp. 143-152, January/February, 2004.

[24]. J.-S. Lai, X. Huang, S. Chen, T. W. Nehl, EMI Characterization and Simulation With Parasitic Models for a Low-Voltage High-Current AC Motor Drive, in IEEE Trans. on Ind. Applications, vol. 40, N. ${ }^{\circ}$ 1, pp. 178-185, January/February, 2004.

[25]. Bologna declaration, http://www.cepes.ro/information_services/sources/on_line/bologna.htm

[26]. Semikron, IPM modules, ref. ${ }^{\text {a }}$ SKiiP 2/3, $\mathrm{http}: / /$ www.semikron.com/internet/index.jsp?sekId=289\&sekNav=228

[27]. Eupec, EiceDRIVER family products, http://www.eupec.com/eicedriver.

[28]. Agilent Technologies, Inc., 2.0 Amp Gate Drive Optocoupler with Integrated $\left(\mathrm{V}_{\mathrm{CE}}\right)$ Desaturation Detection, 2005

[29]. Agilent Technologies, Inc., Optocoupler Designer's Guide - Motor control applications, pp 47, 2004 